OPEN ACCESS

Check for updates

\section{Estimates of all cause mortality and cause specific mortality associated with proton pump inhibitors among US veterans: cohort study}

\author{
Yan Xie, ${ }^{1,2}$ Benjamin Bowe, ${ }^{1,3}$ Yan Yan, ${ }^{1,4}$ Hong Xian, ${ }^{1,3}$ Tingting Li, ${ }^{1,5}$ Ziyad Al-Aly ${ }^{1,2,5,6,7}$
}

${ }^{1}$ Clinical Epidemiology Center, Department of Veterans Affairs St Louis Health Care System, 915 North Grand Boulevard, St Louis, MO 63106, USA

${ }^{2}$ Veterans Research and Education Foundation of St Louis, St Louis, MO, USA

${ }^{3}$ Department of Biostatistics, College for Public Health and University, St Louis, MO, USA

${ }^{4}$ Division of Public Health Sciences, Department of School of Medicine, St Louis, MO, USA

${ }^{5}$ Department of Medicine, Medicine, St Louis, MO, USA

${ }^{6}$ Renal Section, Medicine Service, Department of Veterans Affairs Saint Louis Health Care System, St Louis, MO, USA ${ }^{7}$ Institute for Public Health, Medicine, St Louis, MO, USA

Correspondence to: Z Al-Aly zalaly@gmail.com

(or @zalaly on Twitter; ORCID 0000-0002-2600-0434)

Cite this as: BMJ 2019;365:l1580 http://dx.doi.org/10.1136/bmj.l1580

Accepted: 20 March 2019 Social Justice, Saint Louis Surgery, Washington University Washington University School of Washington University School of

\section{ABSTRACT}

\section{OBJECTIVE}

To estimate all cause mortality and cause specific mortality among patients taking proton pump inhibitors (PPIs).

DESIGN

Longitudinal observational cohort study.

SETTING

US Department of Veterans Affairs.

\section{PARTICIPANTS}

New users of PPIs $(n=157625)$ or $\mathrm{H} 2$ blockers $(n=56842)$.

\section{MAIN OUTCOME MEASURES}

All cause mortality and cause specific mortality associated with taking PPIs (values reported as number of attributable deaths per 1000 patients taking PPIs).

\section{RESULTS}

There were 45.20 excess deaths ( $95 \%$ confidence interval 28.20 to 61.40 ) per 1000 patients taking PPIs. Circulatory system diseases (number of attributable deaths per 1000 patients taking PPIs $17.47,95 \%$ confidence interval 5.47 to 28.80 ), neoplasms (12.94, 1.24 to 24.28 ), infectious and parasitic diseases $(4.20,1.57$ to 7.02$)$, and genitourinary system diseases $(6.25,3.22$ to 9.24$)$ were associated with taking PPIs. There was a graded relation between cumulative duration of PPI exposure and the risk of all cause mortality and death due to circulatory system diseases, neoplasms, and genitourinary system diseases. Analyses of subcauses of death suggested that taking PPIs was associated with an excess mortality due to cardiovascular disease $(15.48,5.02$ to 25.19$)$ and chronic kidney disease $(4.19,1.56$ to 6.58$)$. Among patients without documented indication for acid suppression drugs $(n=116377)$, taking PPIs was associated with an

\section{WHAT IS ALREADY KNOWN ON THIS TOPIC}

Taking proton pump inhibitors (PPIs) is associated with several serious adverse events and with an increased risk of all cause mortality

\section{WHAT THIS STUDY ADDS}

Taking PPIs is associated with an excess of mortality from cardiovascular disease and chronic kidney disease

Patients without a documented indication for acid suppression drugs have an excess mortality due to cardiovascular disease, chronic kidney disease, and upper gastrointestinal cancer

Previous history of cardiovascular disease, chronic kidney disease, and upper gastrointestinal cancer do not modify the relation between PPI use and the risk of death due to cardiovascular disease, chronic kidney disease, and upper gastrointestinal cancer, respectively excess mortality due to cardiovascular disease (22.91, 11.89 to 33.57$)$, chronic kidney disease $(4.74,1.53$ to 8.05), and upper gastrointestinal cancer $(3.12,0.91$ to 5.44). Formal interaction analyses suggested that the risk of death due to these subcauses was not modified by a history of cardiovascular disease, chronic kidney disease, or upper gastrointestinal cancer. Taking PPIs was not associated with an excess burden of transportation related mortality and death due to peptic ulcer disease (as negative outcome controls).

\section{CONCLUSIONS}

Taking PPIs is associated with a small excess of cause specific mortality including death due to cardiovascular disease, chronic kidney disease, and upper gastrointestinal cancer. The burden was also observed in patients without an indication for PPI use. Heightened vigilance in the use of PPI may be warranted.

\section{Introduction}

Proton pump inhibitors (PPIs) are widely used either as prescription or over-the-counter drugs. ${ }^{12}$ Several studies suggest that taking PPIs is associated with a number of serious adverse events including cardiovascular disease, acute kidney injury, chronic kidney disease, dementia, pneumonia, gastric cancer, Clostridium difficile infections, and osteoporotic fractures. ${ }^{3}$ Some of these adverse events are associated with an increased risk of death. Recent studies described an excess risk of all cause mortality among patients taking PPIs. ${ }^{4}$ However, a detailed quantitative analysis of the cause specific mortality that is attributable to taking PPIs is not available. We hypothesized that taking PPIs is associated with an increased risk of cause specific mortality that are mapped to well characterized adverse events of PPIs. Identification of specific causes of death attributable to taking PPIs will inform the public about the risk of taking PPIs in the long term and could inform risk stratification, risk mitigation strategies, and help shape the development of deprescription interventions to reduce unnecessary or un-indicated PPI use. In this work, we built a longitudinal cohort of 214467 United States veterans that were new users of acid suppression drugs - histamine $\mathrm{H} 2$ receptor antagonists ( $\mathrm{H} 2$ blockers) or PPIs-and developed analytic strategies to estimate the all cause mortality and cause specific mortality associated with taking PPIs.

\section{Methods}

Overall study design and specification of a target trial

We designed the cohort, exposure definitions, covariate choices, outcome definitions, and an 
analytic strategy based on the framework proposed by Hernán and Robins. ${ }^{5}$ We emulated a target randomized controlled trial of the comparative effect of new use of PPIs versus $\mathrm{H} 2$ blockers on the risk of all cause and cause specific mortality (details of the specified target trial protocol are presented in supplemental table 1). We then employed causal inference strategies to estimate the mortality attributable to PPI use (further described in the methods and in supplemental table 1).

\section{Cohort design}

We selected new users of acid suppression drugs between 1 July 2002 and 30 June 2004 and followed them for up to 10 years to examine the associations between new use of PPIs and causes of death. New use was defined as having no record of an acid suppression drug prescription between 1 October 1999 and 30 June 2002.

There were 405490 new users of PPIs. To reduce the probability of misclassification, we further selected from this cohort 201557 patients who were prescribed more than a 90 day supply of a PPI in the 180 day period after new PPI use. Additionally, 24061 patients were excluded because they were taking $\mathrm{H} 2$ blockers during the 180 day period, resulting in 177496 new users of PPI.

There were 212735 new users of $\mathrm{H} 2$ blockers and 69731 of them were prescribed more than a 90 day supply in the 180 day period after new $\mathrm{H} 2$ blocker use. In this group of patients, 9528 were excluded because they were taking PPIs during the 180 day period, resulting in 60203 new users of $\mathrm{H} 2$ blockers.

In the two groups of new users of acid suppression drugs, 234950 patients had known sex, race, and date of birth and were alive after 180 days of their first record of prescription. We selected new users whose prescribing physician had also prescribed PPIs or $\mathrm{H} 2$ blockers to other new users within the one year before the cohort patient's first acid suppressant drug prescription, to facilitate building an instrumental variable. We further selected new users whose prescribing facility and clinic are known, yielding a final cohort of 214467 patients (fig 1).

\section{Data sources}

We used Department of Veterans Affairs databases in the study. ${ }^{6}$ The Department of Veterans Affairs operates the largest integrated healthcare system in the US-a veteran specific national health service-to discharged veterans of the US armed forces. ${ }^{7}$ The Department of Veterans Affairs provides a broad range of healthcare at 1400 healthcare facilities, including 143 Department of Veterans Affairs hospitals and 1241 outpatient sites of care of varying complexity to over 9 million veterans (estimated in 2018) enrolled in the Department of Veterans Affairs healthcare program. ${ }^{7-9}$ All enrolled veterans have access to the Department of Veterans Affairs's comprehensive medical benefits package including inpatient hospital care; outpatient services; preventive, primary, and specialty care; prescriptions; mental healthcare; home healthcare; geriatric and extended care; medical equipment; and prosthetics. ${ }^{89}$

We used medical SAS datasets from the Department of Veterans Affairs corporate data warehouse, which provided data on inpatient and outpatient encounters, to obtain information about demographic characteristics, healthcare system and clinic encounters, comorbidities, procedures, and surgeries. ${ }^{10-17}$ We also collected demographic information from the Department of Veterans Affairs Vital Status databases. ${ }^{6}$ The Department of Veterans Affairs Managerial Cost Accounting System Laboratory Results from Department of Veterans Affairs corporate data warehouse provided laboratory results of cohort patients. ${ }^{10-14}$ 17-20 The Department of Veterans Affairs corporate data warehouse Outpatient Pharmacy domain provided outpatient prescription records and an identifier for the hospital and Veterans Integrated Service Network in which the prescription was provided. ${ }^{421-23}$ Additionally, we used National Death Index data to collect information about date of death and the underlying cause of death. ${ }^{24}$

\section{Outcomes}

Study outcomes were specific causes of death based on national death index underlying cause of death coded based on ICD-10 (international classification of diseases, 10th revision). ${ }^{24}$ Causes of death were categorized into the following categories: circulatory system diseases; neoplasms; respiratory system diseases; external causes; endocrine, nutritional, and metabolism diseases; nervous system diseases; digestive system diseases; mental and behavioral disorders; genitourinary system diseases; infectious and parasitic diseases; and other causes. Based on results from causes of death, we further defined subcauses of death within those categories which exhibited statistical significance and for which there existed well characterized evidence supporting a relation between taking PPIs and adverse events which could be associated with cause specific mortality. ${ }^{3}$ These subcauses included death due to cardiovascular diseases, upper gastrointestinal cancer, Clostridium difficile infections, and chronic kidney disease. ${ }^{3}$

\section{Exposure}

We applied an intention to treat design for new use of acid suppressant drugs. Intention to treat with PPIs was defined as a prescription of more than a 90 day supply of a PPI in the 180 day period since first prescription, and with no $\mathrm{H} 2$ blocker prescriptions within this period. Intention to treat with $\mathrm{H} 2$ blockers, which served as an active comparator control, was defined as a prescription of more than a 90 day supply of an $\mathrm{H} 2$ blocker in the 180 day period since first prescription, and with no PPI prescriptions within this period. Use of an active comparator, compared with a non-user control, allows for comparison to those who were prescribed another drug with similar indications; this approach might increase the overlap of characteristics between groups, and might reduce the potential for 


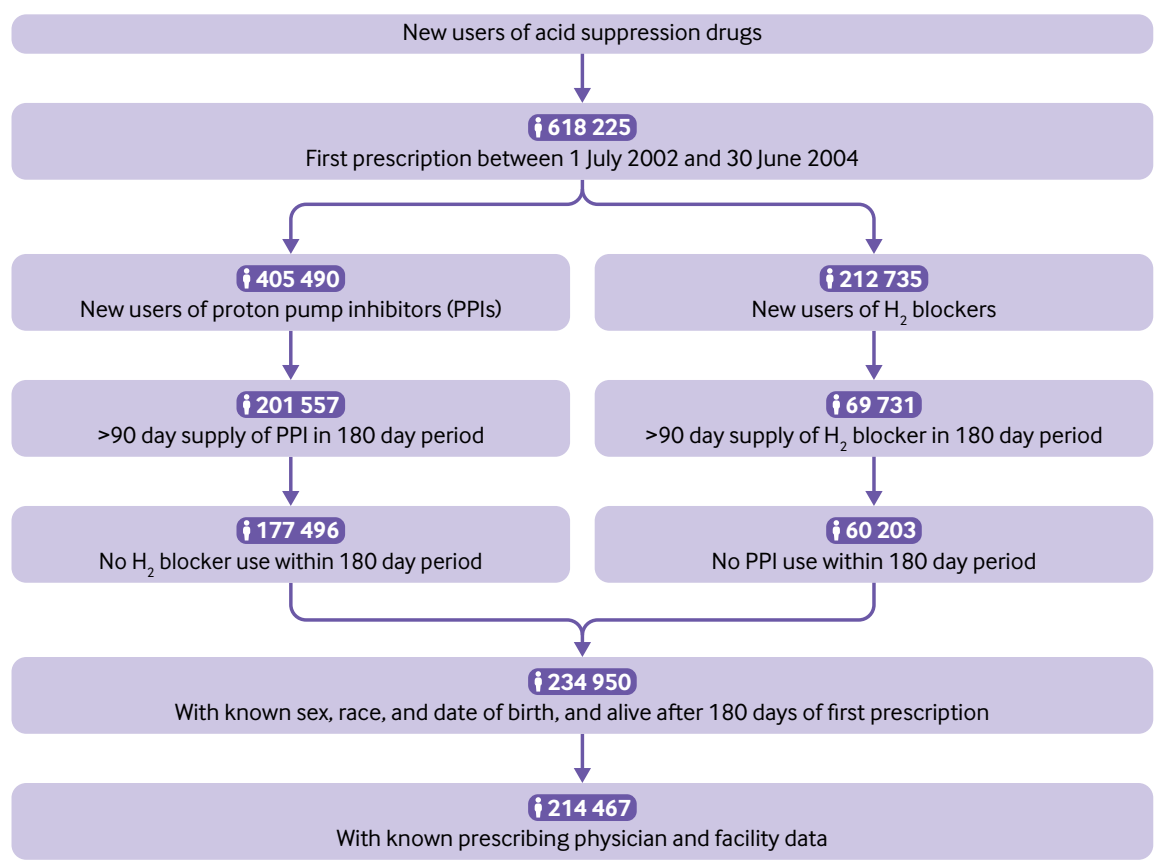

Fig 1 | Flowchart for cohort building

confounding by indication. ${ }^{26}$ In all analyses, we used days of supply as an indication of number days with a prescription.

\section{Covariates}

We collected covariates within one year before the first acid suppressant prescription. We selected basic demographics, health service utilization characteristics, and indications for prescription of acid suppressant drugs based on previous knowledge including age, sex, race, year of first prescription, number of outpatient visits, total length of stay in hospital, level of complexity of the hospital in which the prescription was provided, type of clinic in which the prescription was provided, location of the hospital where the prescription was provided, gastresophageal reflux disease, upper gastrointestinal tract bleeding, ulcer disease, $\mathrm{H}$ pylori infection, Barrett's esophagus, achalasia, stricture, and esophageal adenocarcinoma. ${ }^{416172728}$ Age, number of outpatient visits and total length of stay hospital were modeled as cubic spline functions. Level of hospital complexity was defined as outpatient clinic, medical center, and healthcare system. Clinic type was defined as gastroenterology, primary care, and other. Location of hospital was defined by the Veterans Integrated Service Network. ${ }^{29} 30$ To more closely emulate our target trial, which would have random assignment of acid suppressant drug, and to reduce bias from non-random assignment by reducing imbalances in patient characteristics between PPIs and $\mathrm{H} 2$ blockers, we built a high dimensional propensity score using pre-exposure information in domains including outpatient ICD-9 (international classification of diseases, ninth revision) diagnoses, outpatient Current Procedural Terminology codes, inpatient ICD-9 diagnoses, inpatient procedures, inpatient surgeries, and outpatient pharmacy and laboratory records. ${ }^{31}$ We used physicians' prescribing preference as an instrumental variable to reduce the probability that an observed association (between PPIs and causes of death) is contributed by unmeasured confounders. ${ }^{32} 33$

\section{Statistical analyses}

Characteristics and outcome events of cohort patients for the PPI and $\mathrm{H} 2$ blocker groups are reported as number and percentage, mean and standard deviation, or median and interquartile range, as appropriate. Kaplan-Meier curves of all cause mortality in new users of PPIs and $\mathrm{H} 2$ blockers are presented.

To more closely mimic a target trial where new use of PPIs and $\mathrm{H} 2$ blockers is randomly assigned, we used the approach developed by Schneeweiss and colleagues to generate high dimensional propensity scores. This approach selects potential confounders among those included in our data domains based on their relative association for new use of PPIs compared with new use of $\mathrm{H} 2$ blockers. ${ }^{3134}$ We then used predefined covariables and algorithmically selected covariates together to generate propensity scores. ${ }^{35}{ }^{36}$ We applied inverse treatment probability weights based on the propensity scores to the cohort, which results in a weighted pseudo cohort where treatment assignment is independent of measured confounders. ${ }^{37}$ For the PPIs and H2 blockers groups, plots of the distributions of the propensity scores and standardized differences before and after weighting are provided in supplemental figures $1 \mathrm{a}-\mathrm{c}$.

To reduce bias from unmeasured confounding, we applied instrumental variable analyses using the twostage residual inclusion method to the weighted pseudo cohort. ${ }^{3233}$ We used physician-specific prescribing 
preference as the instrumental variable to account for unmeasured confounders that might not be accounted for in the high dimensional propensity score, which could include severity of diseases and other treatment indications. ${ }^{39}$ In the first stage, the residual between the observed and predicted probability of receiving the assigned treatment given instrumental variable was computed from logistic regression weighted by inverse treatment probability weights based on high dimensional propensity scores. In the second stage, we used the residual as an independent variable indicating unmeasured confounders in the inverse treatment probability weighted cause specific Cox survival analyses and Fine and Gray survival analyses. Physician prescription preferences in past patients has been used as an instrumental variable in the conduction of pharmacoepidemiologic studies. ${ }^{39} 4041$ To assess the strength of our instrumental variable, we conducted a logistic regression of the odds of being prescribed PPIs versus $\mathrm{H} 2$ blockers. Results suggested that a $10 \%$ increase in a physician prescribing preference toward prescribing PPIs in past patients was associated with a 35\% (95\% confidence interval $35 \%$ to $35 \%$ ) increase in odds of the current patient being prescribed PPIs compared with $\mathrm{H} 2$ blockers after adjustment for patient characteristics at the time of prescription. These results suggest that we do not have a weak instrumental variable. Further discussion on instrumental variable assumptions can be found in the supplemental methods.

We also applied negative and positive controls to examine if potential biases could have modified the relation between PPI use and cause specific mortality. We examined acute kidney injury as a positive outcome control, where previous studies have shown a relation with PPIs. ${ }^{22}$ We examined transportation related death as a negative outcome control following the approach described by Lipsitch and colleagues, where-based on current knowledge-we assumed that there should be no causal relation between PPI use and transportation related mortality. ${ }^{42}$ The relation of this exposureoutcome pair could share the same potential biases with PPIs and other cause specific deaths including unmeasured confounders, modeling algorithms, exposure measurement, outcome ascertainments, and other biases. ${ }^{42}$ We also applied death due to peptic ulcer disease as an additional negative outcome control, where, based on previous knowledge, we expect that PPI users should not have a higher risk of death due to peptic ulcer disease if treatment by indication has been accounted for; the choice of this outcome control was motivated by the fact that peptic ulcer disease is an underlying indication for PPI use and that the relation between this exposure-outcome pair could have the same potential bias as PPIs and other outcomes in the field of treatment by indication. ${ }^{43}$

In addition to the intention to treat design, since a proportion of new users of $\mathrm{H} 2$ blockers used PPIs later during follow-up, we conducted a sensitivity analyses that examined PPI ever-use as a time varying exposure. We also conducted a duration analysis in new users of PPIs where cumulative exposure was defined as the total number of days of PPI supply up to the last day of prescription. To address immortal time bias, the $\mathrm{T}_{0}$ in this analysis was set to be the end of the last prescription. $^{4}$

To further evaluate cause specific mortality, we analyzed detailed subcauses of death (as detailed in the outcomes section). In addition, to remove potential confounding by gastrointestinal disease severity, we repeated the analyses in a sub cohort where patients had no documented gastrointestinal indications for acid suppression drugs before receipt of the first prescription. Moreover, we conducted formal interaction analyses to examine whether the presence of a baseline comorbid condition modified the relation between new PPI use and its related cause specific mortality.

Main results are reported as the event rate per 100 people in the PPIs and $\mathrm{H} 2$ blockers groups, and as estimated excess burden associated with new use PPI per 1000 people based on estimated cumulative incidence rate probability at 10 years. To account for the impact on variance that results from inverse probability of treatment weighting and two stage residual inclusion methods, ${ }^{33} 44$ we analyzed 1000 bootstrapped samples, and report the 2.5 and 97.5 centiles as $95 \%$ confidence intervals.

A 95\% confidence interval that does not cross 0 for absolute risk and does not cross 1 for ratio was considered statistically significant. Figure 2 and the supplemental methods show a detailed description of the analytic approach. All analyses were done using SAS Enterprise Guide version 7.1 (SAS Institute, Cary, NC). The study was approved by the Institutional Review Board of the Department of Veterans Affairs St Louis Health Care System, St Louis, MO.

\section{Patient and public involvement}

No patients were involved in developing the hypothesis, the specific aims, or the research questions, nor were they involved in developing plans for design or implementation of the study. No patients were involved in the interpretation or writing up of results. There are no plans to disseminate the results of the research to study participants.

\section{Results}

Table 1 shows the demographic and health characteristics of the overall cohort of new users of acid suppression drugs $(n=214467)$, by the type of acid suppressant drug at the time of cohort entry (PPIs, $\mathrm{n}=157625$; H2 blockers, $\mathrm{n}=56842$ ). In the overall cohort, the average age was $65.10( \pm 12.25), 95.93 \%$ were male, and $87.43 \%$ were white. Table 2 and supplemental table 2 show that among new users of PPIs, rabeprazole $20 \mathrm{mg}$ once a day, omeprazole 20 mg once a day, and rabeprazole $20 \mathrm{mg}$ twice a day accounted for $58.78 \%, 21.66 \%$, and $8.41 \%$ of all initial PPI prescriptions, respectively. Over a median duration of follow up of 10 years (interquartile range $6.95-10.00)$, there were $80062(37.33 \%)$ deaths. 


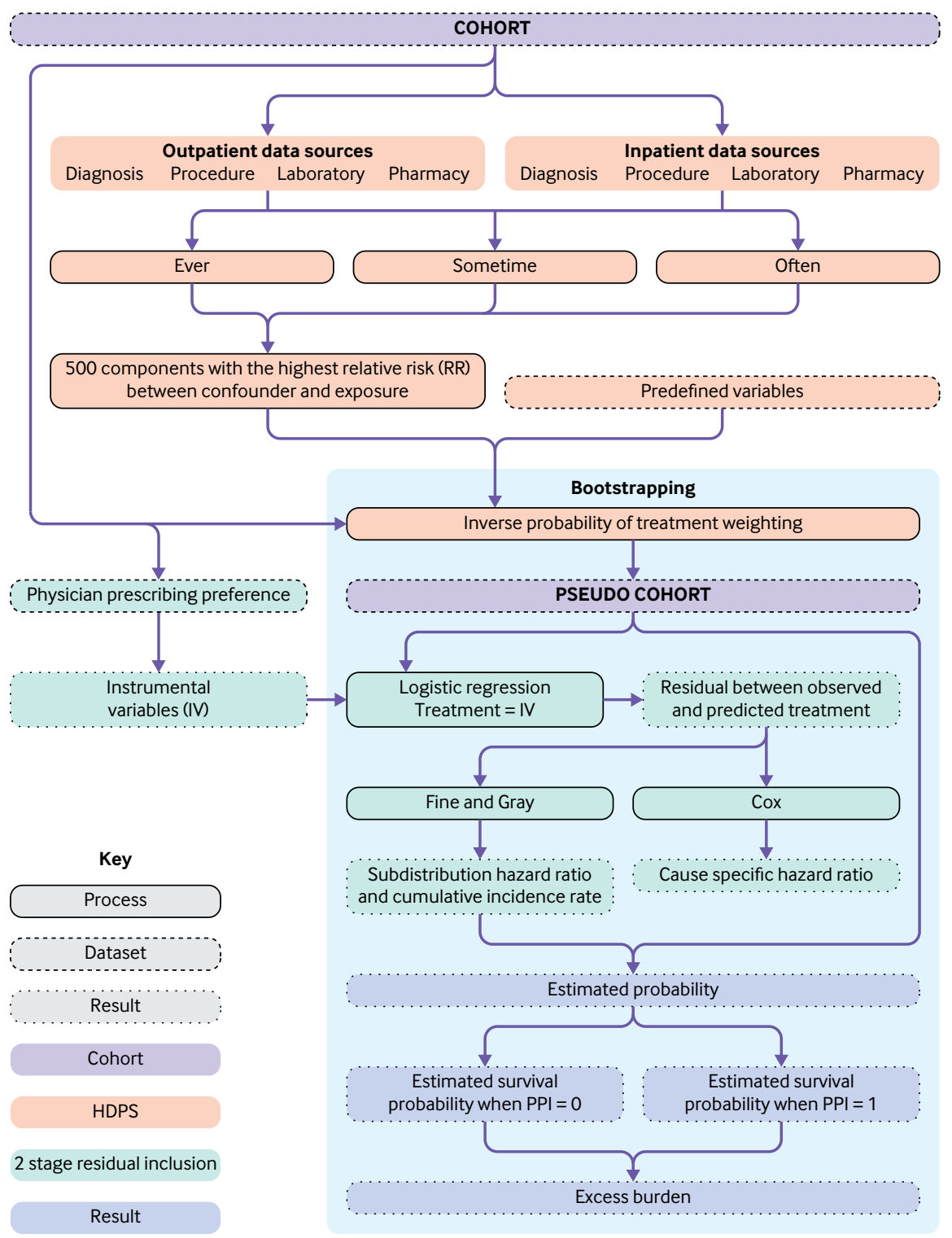

Fig 2 | Flowchart for analytic approach

The most common causes of death were circulatory system diseases (12.45\%), neoplasms (9.72\%), and respiratory system diseases $(4.80 \%)$. There were more deaths among patients taking PPIs than those taking $\mathrm{H} 2$ blockers $(37.92 \%$ and $35.69 \%$, respectively). Table 1 shows that the median time-todeath was 4.84 (interquartile range $2.35-7.38$ ) and 4.96 (2.49-7.48) years in the PPIs and H2 blockers groups, respectively. Kaplan-Meier curves for the PPIs and $\mathrm{H} 2$ blockers new use groups are presented in supplemental figure 2 .

\section{Development of a target trial and application of positive and negative controls}

To estimate the association between exposure to PPIs and causes of death, we aimed to emulate a target trial where patients would be randomly assigned to new use of PPIs or $\mathrm{H} 2$ blockers for more than 90 days (supplemental table 1). We followed the approach outlined by Hernán and Robins of using big data to emulate a target trial when a randomized trial is not available ${ }^{5}$; we designed a multipronged approach involving several strategies detailed in supplemental table 1. To further resolve concerns about spurious associations, we first applied a positive control to examine the association between exposure to PPIs and the risk of acute kidney injury where a priori knowledge suggests an association is expected. ${ }^{342122}$ Table 3 shows that the results suggested that exposure to PPIs was associated with an increased burden of acute kidney injury (number of attributable cases per 1000 PPI users $15.03,95 \%$ confidence interval 1.17 to 29.85). We then tested two negative controls following the approach outlined by Lipsitch and colleagues. ${ }^{42}$ We first examined the association between PPI use and transportation related death where the relation of this exposure-outcome pair could share the same potential biases with PPIs and other cause specific deaths. Table 


\begin{tabular}{|c|c|c|c|}
\hline Characteristic & Overall & PPIs & H2 blockers \\
\hline Total & 214467 & $157625(73.50)$ & $56842(26.50)$ \\
\hline Mean (SD) age (years) & $65.10(12.25)$ & $65.51(12.14)$ & $63.97(12.46)$ \\
\hline \multicolumn{4}{|l|}{ Sex: } \\
\hline Men & $205748(95.93)$ & $151399(96.05)$ & $54349(95.61)$ \\
\hline Women & $8719(4.07)$ & $6226(3.95)$ & $2493(4.39)$ \\
\hline \multicolumn{4}{|l|}{ Race: } \\
\hline White & $187519(87.43)$ & $138967(88.16)$ & $48552(85.42)$ \\
\hline Black & $20089(9.37)$ & $14193(9.00)$ & $5896(10.37)$ \\
\hline Other & $6859(3.20)$ & $4465(2.83)$ & $2394(4.21)$ \\
\hline Admitted to hospital in past year & $20794(9.70)$ & $15221(9.66)$ & $5573(9.80)$ \\
\hline Median (IQR) length of stay among inpatients (days) & $7(4$ to 13$)$ & $7(4$ to 13$)$ & $7(4$ to 14$)$ \\
\hline Median (IQR) no of outpatient visits & $4(1$ to 10$)$ & $4(1$ to 10$)$ & $5(2$ to 11$)$ \\
\hline \multicolumn{4}{|l|}{ Disease: } \\
\hline Diabetes mellitus & $48869(22.79)$ & $35777(22.70)$ & $13092(23.03)$ \\
\hline Hypertension & $116536(54.34)$ & $85136(54.01)$ & $31400(55.24)$ \\
\hline Chronic lung disease & $29517(13.76)$ & $21588(13.70)$ & $7929(13.95)$ \\
\hline Peripheral artery disease & $2475(1.15)$ & $1745(1.11)$ & $720(1.28)$ \\
\hline Cardiovascular disease & $54122(25.24)$ & $40641(25.78)$ & $13481(23.72)$ \\
\hline Dementia & $4747(2.21)$ & $3420(2.17)$ & $1327(2.33)$ \\
\hline Hyperlipidemia & $90812(42.34)$ & $66613(42.26)$ & $24199(42.57)$ \\
\hline Hepatitis C & $1953(0.91)$ & $1403(0.89)$ & $550(0.97)$ \\
\hline HIV & $57(0.03)$ & $37(0.02)$ & $20(0.04)$ \\
\hline Cancer & $9738(4.54)$ & $7465(4.74)$ & $2273(4.00)$ \\
\hline $\begin{array}{l}\text { Any documented gastrointestinal indication for acid suppression } \\
\text { drugs }\end{array}$ & $98090(45.74)$ & $76581(48.58)$ & $21509(37.84)$ \\
\hline Gastresophageal reflux disease & 83904 (39.12) & $64602(40.98)$ & $19302(33.96)$ \\
\hline Upper gastrointestinal tract bleeding & $3356(1.56)$ & $3072(1.95)$ & $284(0.50)$ \\
\hline Ulcer disease & $13856(6.46)$ & $11585(7.35)$ & $2271(4.00)$ \\
\hline $\mathrm{H}$ pylori infection & $809(0.38)$ & $746(0.47)$ & $63(0.11)$ \\
\hline Barrett's esophagus & $597(0.28)$ & $588(0.37)$ & $9(0.02)$ \\
\hline Achalasia & $66(0.03)$ & $60(0.04)$ & $6(0.01)$ \\
\hline Stricture & $1288(0.60)$ & $1202(0.76)$ & $86(0.15)$ \\
\hline Esophageal adenocarcinoma & $42(0.02)$ & $36(0.02)$ & $6(0.01)$ \\
\hline \multicolumn{4}{|l|}{ Drugs: } \\
\hline $\begin{array}{l}\text { Angiotensin converting enzyme inhibitors or angiotensin receptor } \\
\text { blockers }\end{array}$ & $84832(39.34)$ & $62306(39.53)$ & $22076(38.84)$ \\
\hline Statins & $86546(40.35)$ & $64440(40.88)$ & $22106(38.89)$ \\
\hline Nonsteroidal anti-inflammatory drugs & $56346(26.27)$ & $38945(24.71)$ & $17401(30.61)$ \\
\hline Mean (SD) estimated glomerular filtration rate $\left(\mathrm{mL} / \mathrm{min} / 1.73 \mathrm{~m}^{2}\right)$ & $73.43(21.03)$ & $72.88(21.14)$ & $74.84(20.69)$ \\
\hline Median (IQR) HbA1C (\%) & $6.2(5.6-7.3)$ & $6.2(5.6-7.2)$ & $6.2(5.6-7.3)$ \\
\hline Mean (SD) systolic blood pressure (mmHg) & $137.19(19.64)$ & $137.09(19.64)$ & $137.49(19.63)$ \\
\hline Mean (SD) diastolic blood pressure $(\mathrm{mmHg})$ & $76.17(11.79)$ & $75.97(11.80)$ & $76.74(11.76)$ \\
\hline Median (IQR) high density lipoprotein (mg/dL) & $41.87(35.00-50.00)$ & $41.60(35.00-50.00)$ & $42.00(35.00-50.00)$ \\
\hline Median (IQR) low density lipoprotein (mg/dL) & $107.0(86.0-131.4)$ & $106.3(85.0-131.0)$ & $109.6(88.0-133.0)$ \\
\hline \multicolumn{4}{|l|}{ Smoking status: } \\
\hline Current & 41809 (19.49) & $28928(18.35)$ & $12881(22.66)$ \\
\hline Former & $44216(20.62)$ & $34247(21.73)$ & $9969(17.54)$ \\
\hline Never & $128442(59.89)$ & $94450(59.92)$ & $33992(59.80)$ \\
\hline Median (IQR) washout period (days) & $728(174-1584)$ & $675(158-1565)$ & $889(230-1631)$ \\
\hline Median (IQR) years of follow-up & $10.00(6.59-10.00)$ & $10.00(6.45-10.00)$ & $10.00(6.95-10.00)$ \\
\hline Median (IQR) days of PPI prescription during follow-up & $1278(354-2591)$ & $1682(682-2879)$ & $123(0-1288)$ \\
\hline Median (IQR) days of $\mathrm{H} 2$ blocker prescription during follow-up & $0(0-270)$ & $0(0-0)$ & $597(270-1299)$ \\
\hline Median (IQR) time-to-death (years) & $4.87(2.39-7.40)$ & $4.84(2.35-7.38)$ & $4.96(2.49-7.48)$ \\
\hline All cause mortality & $80062(37.33)$ & $59776(37.92)$ & $20286(35.69)$ \\
\hline \multicolumn{4}{|l|}{ Cause specific mortality: } \\
\hline Circulatory system diseases & $26711(12.45)$ & $19923(12.64)$ & $6788(11.94)$ \\
\hline Neoplasms & $20847(9.72)$ & $15529(9.85)$ & $5318(9.36)$ \\
\hline Respiratory system diseases & $10294(4.80)$ & $7593(4.82)$ & $2701(4.75)$ \\
\hline External causes & $3406(1.59)$ & $2483(1.58)$ & $923(1.62)$ \\
\hline Endocrine, nutritional, and metabolism diseases & $3581(1.67)$ & $2628(1.67)$ & $953(1.68)$ \\
\hline Nervous system diseases & $3391(1.58)$ & $2574(1.63)$ & $817(1.44)$ \\
\hline Digestive system diseases & $3299(1.54)$ & $2552(1.62)$ & $747(1.31)$ \\
\hline Mental and behavioral disorders & $2114(0.99)$ & $1664(1.06)$ & $450(0.79)$ \\
\hline Genitourinary system diseases & $2373(1.11)$ & $1827(1.16)$ & $546(0.96)$ \\
\hline Infectious and parasitic diseases & $2114(0.99)$ & $1664(1.06)$ & $450(0.79)$ \\
\hline Symptoms, signs, and abnormal clinical or labor & $789(0.37)$ & $588(0.37)$ & $201(0.35)$ \\
\hline
\end{tabular}




\begin{tabular}{llll}
\hline Table 1 | Continued & & & \\
Characteristic & Overall & PPIs & H2 blockers \\
\hline Musculoskeletal system diseases & $342(0.16)$ & $267(0.17)$ & $75(0.13)$ \\
\hline Blood diseases & $287(0.13)$ & $223(0.14)$ & $64(0.11)$ \\
\hline Skin and subcutaneous diseases & $113(0.05)$ & $75(0.05)$ & $38(0.07)$ \\
\hline Congenital malformations & $44(0.02)$ & $33(0.02)$ & $11(0.02)$ \\
\hline Ear and mastoid diseases & $4(0.00)$ & $3(0.00)$ & $1(0.00)$ \\
\hline Eye diseases & $2(0.00)$ & $2(0.00)$ & $0(0.00)$ \\
\hline$\quad$ Nonspecific* & $21(0.01)$ & $18(0.01)$ & $3(0.01)$ \\
\hline $\begin{array}{l}\text { PPIs=proton pump inhibitors; IQR=interquartile range } \\
\text { *Underlying cause of death missing }\end{array}$ & & & \\
\end{tabular}

3 shows that PPI exposure was not associated with excess burden of transportation related death $(-0.21$, -2.96 to 2.48). To verify that indication bias was accounted for, we then estimated the mortality due to peptic ulcer disease-an underlying indication for PPI use-as an additional negative outcome control where the relation between this exposure-outcome pair might share the same potential biases as PPIs and outcomes in the area of treatment by indication; the results showed no excess of peptic ulcer disease related death $(-0.46,-2.43$ to 0.27$)$ suggesting that indication bias might have been accounted for.

\section{Causes of death among patients taking PPIs}

We then used our analytic approach to estimate the excess cause specific mortality burden associated with new use of PPIs. Details of the model construction are presented in figure 2 and supplemental table 1. Our results suggest that over the course of 10 years of follow-up there were 45.52 (95\% confidence interval 28.20 to 61.40) excess deaths per 1000 PPI users. Table 4 shows that over the follow-up period of 10 years, causes of death which exhibited significant excess mortality associated with PPI use included circulatory system diseases (number of attributable deaths per 1000 PPI users 17.47, 95\% confidence interval 5.47 to 28.80 ), neoplasms $(12.94,1.24$ to $24.28)$, genitourinary system diseases $(6.25,3.22$ to 9.24), and infectious and parasitic diseases (4.20, 1.57 to 7.02). Notably, taking PPIs was not associated with increased mortality due to digestive system diseases $(0.43,-3.72$ to 4.07$)$. The results were consistent in sensitivity analyses where exposure was treated as time varying (supplemental table 3 ).

Table 5 shows that in analyses evaluating the relation between cumulative duration of exposure and the risks of all cause and cause specific mortality, there was a graded relation between duration of exposure and risks of all cause mortality, death due to circulatory system diseases, neoplasms, and genitourinary system diseases. The risk of death due to infectious and parasitic diseases was not related to duration of exposure.

\section{Subcauses of death}

Because our results showed excess deaths due to circulatory system diseases, neoplasms, genitourinary system diseases, and infectious and parasitic diseases, we further examined excess death in subcauses of these conditions which could be mapped to adverse events of PPIs, which are well characterized. These subcauses included death due cardiovascular diseases, upper gastrointestinal cancer, Clostridium difficile infections, and chronic kidney disease. ${ }^{3}$ Table 6 shows that we observed excess deaths due to cardiovascular disease (number of attributable deaths per 1000 PPI users 15.48 , 95\% confidence interval 5.02 to 25.19) and chronic kidney disease $(4.19,1.56$ to 6.58$)$, but not due to upper gastrointestinal cancer $(1.72,-0.15$ to 3.74) or Clostridium difficile infections (0.65, -0.18 to 1.70$)$.

We examined the association between PPI use and the four subcauses in patients without documented gastrointestinal indication for acid suppression drugs. Table 7 shows that there is an excess of cause specific mortality associated with taking PPIs for cardiovascular diseases (number of attributable deaths per 1000 PPI users 22.91 , 95\% confidence interval 11.89 to 33.57 ), upper gastrointestinal cancer (3.12, 0.91 to 5.44), and chronic kidney disease (4.74, 1.53 to 8.05$)$.

Formal interaction analyses were undertaken to evaluate whether the presence of baseline cardiovascular disease, upper gastrointestinal cancer, or chronic kidney disease modified the association between PPI use and the related subcauses of death. Results suggest no significant interaction for death due to cardiovascular diseases ( $\mathrm{P}=0.22$ for interaction), upper gastrointestinal cancer $(\mathrm{P}=0.54$ for interaction), and chronic kidney disease ( $\mathrm{P}=0.10$ for interaction). Interaction analyses between PPI use and history of Clostridium difficile infections could not be conducted because no patients in the $\mathrm{H} 2$ blockers group with

\begin{tabular}{|c|c|c|c|c|}
\hline \multirow[b]{2}{*}{ Rank } & \multicolumn{2}{|c|}{ PPIs } & \multicolumn{2}{|c|}{ H2 blockers } \\
\hline & Prescription & N (\%) & Prescription & N (\%) \\
\hline 2 & Omeprazole 20 mg once a day & $34149(21.66)$ & Ranitidine $150 \mathrm{mg}$ once a day & $8225(14.47)$ \\
\hline 3 & Rabeprazole 20 mg twice a day & $13250(8.41)$ & Ranitidine $300 \mathrm{mg}$ twice a day & $3156(5.55)$ \\
\hline
\end{tabular}




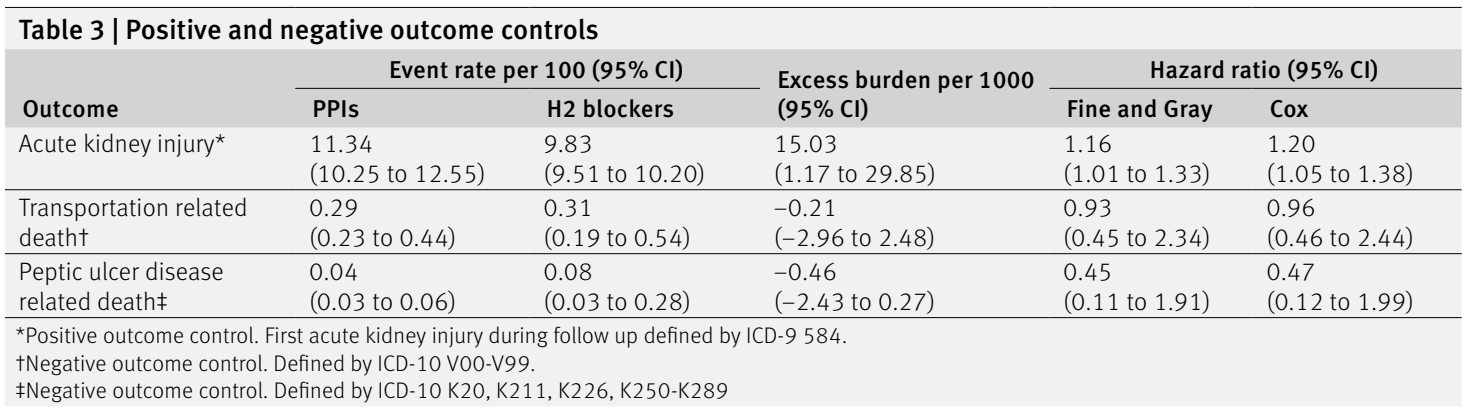

history of Clostridium difficile infections experienced death due to Clostridium difficile.

\section{Discussion}

We examined the causes of death associated with new use of PPIs in a longitudinal observational cohort of US veterans. Overall, there were 45.20 attributable deaths per 1000 PPI users; $38.65 \%$ were related to circulatory system diseases, $28.63 \%$ to neoplasms, $13.83 \%$ to genitourinary system diseases, and $9.29 \%$ to infectious and parasitic diseases. Analyses by subcauses of death suggest that new use of PPIs is associated with an excess of mortality from cardiovascular disease and chronic kidney disease; this pattern was consistent in analyses considering those without documented indication for acid suppression drugs. Increased risk of death due to upper gastrointestinal cancer was more evident in those without documented indication for acid suppression drugs. The risk of cause specific mortality was not modified by the presence of previous history of cardiovascular disease, chronic kidney disease, or upper gastrointestinal cancer.

\section{Contextual evaluation of findings}

PPIs are often used without indication and for much longer than needed. ${ }^{45-52}$ Evidence from the past several years suggests that taking PPIs is associated with serious adverse events including cardiovascular disease, pneumonia, osteoporotic fractures, Clostridium difficile infections, acute kidney injury, chronic kidney disease, dementia, and upper gastrointestinal cancer. ${ }^{3}$ We previously described an excess risk of all cause mortality among PPI users. ${ }^{4}$ In this report, we used advanced causal inference methods to identify and estimate the excess of cause specific mortality associated with taking PPIs. Our findings suggest that although PPI use might be associated with many serious adverse events, excess mortality was only mapped to a few specific causes including cardiovascular disease, chronic kidney disease, and upper gastrointestinal cancer. Notably, excess burden was present in those without underlying documented indications for PPI use, that is, patients who may not benefit from PPI exposure. Our results, however, should not preclude prescription and use

\begin{tabular}{|c|c|c|c|c|c|c|}
\hline \multirow[b]{2}{*}{ Cause of death } & \multirow{2}{*}{$\begin{array}{l}\text { ICD- } 10 \text { cause of } \\
\text { death }\end{array}$} & \multicolumn{2}{|c|}{ Event rate per $100(95 \% \mathrm{Cl})$} & \multirow{2}{*}{$\begin{array}{l}\text { Excess burden per } \\
1000(95 \% \mathrm{Cl})\end{array}$} & \multicolumn{2}{|c|}{ Hazard ratio $(95 \% \mathrm{Cl})$} \\
\hline & & PPIs & H2 blockers & & Fine and Gray & Cox \\
\hline All & Any & $\begin{array}{l}38.74 \\
\text { (38.19 to } 39.31 \text { ) }\end{array}$ & $\begin{array}{l}34.22 \\
\text { (33.04 to } 35.46 \text { ) }\end{array}$ & $\begin{array}{l}45.20 \\
(28.20 \text { to } 61.40)\end{array}$ & $\begin{array}{l}1.17 \\
\text { (1.10 to } 1.24)\end{array}$ & $\begin{array}{l}1.17 \\
\text { (1.10 to } 1.24)\end{array}$ \\
\hline $\begin{array}{l}\text { Circulatory system } \\
\text { diseases }\end{array}$ & $100-199$ & $\begin{array}{l}13.10 \\
(12.73 \text { to } 13.49)\end{array}$ & $\begin{array}{l}11.35 \\
\text { (10.54 to } 12.25)\end{array}$ & $\begin{array}{l}17.47 \\
\text { (5.47 to 28.80) }\end{array}$ & $\begin{array}{l}1.17 \\
(1.05 \text { to } 1.29)\end{array}$ & $\begin{array}{l}1.19 \\
\text { (1.07 to } 1.33)\end{array}$ \\
\hline Neoplasms & CO0-D49 & $\begin{array}{l}10.20 \\
\text { (9.81 to 10.64) }\end{array}$ & $\begin{array}{l}8.90 \\
\text { (8.16 to } 9.75)\end{array}$ & $\begin{array}{l}12.94 \\
\text { (1.24 to 24.28) } \\
\end{array}$ & $\begin{array}{l}1.15 \\
\text { (1.01 to } 1.31)\end{array}$ & $\begin{array}{l}1.18 \\
(1.03 \text { to } 1.35) \\
\end{array}$ \\
\hline $\begin{array}{l}\text { Respiratory system } \\
\text { diseases }\end{array}$ & 100-J99 & $\begin{array}{l}4.87 \\
\text { (4.68 to } 5.07)\end{array}$ & $\begin{array}{l}4.65 \\
(4.23 \text { to } 5.19)\end{array}$ & $\begin{array}{l}2.25 \\
(-4.84 \text { to } 8.14)\end{array}$ & $\begin{array}{l}1.05 \\
\text { (0.90 to } 1.2)\end{array}$ & $\begin{array}{l}1.09 \\
\text { (0.94 to 1.24) }\end{array}$ \\
\hline External causes & V00-Y99 & $\begin{array}{l}1.50 \\
\text { (1.38 to } 1.66)\end{array}$ & $\begin{array}{l}1.92 \\
\text { (1.48 to } 2.66)\end{array}$ & $\begin{array}{l}-4.17 \\
(-12.7 \text { to } 1.85) \\
\end{array}$ & $\begin{array}{l}0.78 \\
(0.52 \text { to } 1.12)\end{array}$ & $\begin{array}{l}0.81 \\
(0.54 \text { to } 1.18) \\
\end{array}$ \\
\hline $\begin{array}{l}\text { Endocrine, nutritional, } \\
\text { and metabolism } \\
\text { diseases }\end{array}$ & E00-E89 & $\begin{array}{l}1.61 \\
\text { (1.51 to } 1.71)\end{array}$ & $\begin{array}{l}1.82 \\
\text { (1.53 to } 2.19)\end{array}$ & $\begin{array}{l}-2.11 \\
(-6.51 \text { to } 1.63)\end{array}$ & $\begin{array}{l}0.88 \\
(0.70 \text { to } 1.11)\end{array}$ & $\begin{array}{l}0.91 \\
(0.72 \text { to } 1.14)\end{array}$ \\
\hline $\begin{array}{l}\text { Nervous system } \\
\text { diseases }\end{array}$ & G00-G99 & $\begin{array}{l}1.68 \\
\text { (1.53 to } 1.87)\end{array}$ & $\begin{array}{l}1.39 \\
(1.16 \text { to } 1.72)\end{array}$ & $\begin{array}{l}2.84 \\
(-1.61 \text { to } 6.83)\end{array}$ & $\begin{array}{l}1.21 \\
\text { (0.91 to } 1.59)\end{array}$ & $\begin{array}{l}1.25 \\
\text { (0.94 to } 1.67)\end{array}$ \\
\hline $\begin{array}{l}\text { Digestive system } \\
\text { diseases }\end{array}$ & K00-K99 & $\begin{array}{l}1.54 \\
\text { (1.44 to } 1.66)\end{array}$ & $\begin{array}{l}1.50 \\
\text { (1.24 to } 1.83)\end{array}$ & $\begin{array}{l}0.43 \\
(-3.72 \text { to } 4.07) \\
\end{array}$ & $\begin{array}{l}1.03 \\
(0.79 \text { to } 1.33)\end{array}$ & $\begin{array}{l}1.06 \\
(0.82 \text { to } 1.37)\end{array}$ \\
\hline $\begin{array}{l}\text { Mental and } \\
\text { behavioral disorders }\end{array}$ & F00-F99 & $\begin{array}{l}1.22 \\
\text { (1.11 to } 1.36)\end{array}$ & $\begin{array}{l}1.04 \\
\text { (0.85 to } 1.27)\end{array}$ & $\begin{array}{l}1.82 \\
(-1.45 \text { to } 4.96)\end{array}$ & $\begin{array}{l}1.18 \\
(0.89 \text { to } 1.58)\end{array}$ & $\begin{array}{l}1.23 \\
(0.93 \text { to } 1.66)\end{array}$ \\
\hline $\begin{array}{l}\text { Genitourinary system } \\
\text { diseases }\end{array}$ & N00-N99 & $\begin{array}{l}1.35 \\
\text { (1.21 to } 1.54)\end{array}$ & $\begin{array}{l}0.72 \\
(0.59 \text { to } 0.91)\end{array}$ & $\begin{array}{l}6.25 \\
\text { (3.22 to } 9.24) \\
\end{array}$ & $\begin{array}{l}1.87 \\
\text { (1.35 to } 2.58)\end{array}$ & $\begin{array}{l}1.94 \\
(1.41 \text { to } 2.68) \\
\end{array}$ \\
\hline $\begin{array}{l}\text { Infectious and } \\
\text { parasitic diseases }\end{array}$ & A00-B99 & $\begin{array}{l}1.12 \\
\text { (1.01 to } 1.26)\end{array}$ & $\begin{array}{l}0.70 \\
(0.55 \text { to } 0.88)\end{array}$ & $\begin{array}{l}4.20 \\
\text { (1.57 to } 7.02)\end{array}$ & $\begin{array}{l}1.61 \\
\text { (1.18 to } 2.28)\end{array}$ & $\begin{array}{l}1.66 \\
(1.21 \text { to } 2.35) \\
\end{array}$ \\
\hline Other causes* & $\begin{array}{l}\text { D50-D89, H00-H95, } \\
\text { L00-M99, O00-R99 }\end{array}$ & $\begin{array}{l}0.81 \\
(0.72 \text { to } 0.95)\end{array}$ & $\begin{array}{l}0.60 \\
(0.44 \text { to } 0.85)\end{array}$ & $\begin{array}{l}2.11 \\
(-1.26 \text { to } 5.02) \\
\end{array}$ & $\begin{array}{l}1.35 \\
(0.85 \text { to } 2.16)\end{array}$ & $\begin{array}{l}1.40 \\
(0.88 \text { to } 2.23)\end{array}$ \\
\hline
\end{tabular}

*Death from symptoms, signs, and abnormal clinical or laboratory result; musculoskeletal system diseases; blood diseases; skin and subcutaneous diseases; congenital malformations; ear and mastoid diseases; eye diseases; and nonspecific death 


\begin{tabular}{|c|c|c|c|c|c|}
\hline Duration (days) & Deaths & $\begin{array}{l}\text { Circulatory } \\
\text { system diseases* }\end{array}$ & Neoplasmst & $\begin{array}{l}\text { Genitourinary } \\
\text { system diseases }\end{array}$ & $\begin{array}{l}\text { Infectious and } \\
\text { parasitic diseases§ }\end{array}$ \\
\hline $0-120$ & 1 (ref) & 1 (ref) & 1 (ref) & 1 (ref) & 1 (ref) \\
\hline $121-240$ & $1.23(1.12$ to 1.34$)$ & $1.13(0.97$ to 1.31$)$ & 1.09 (0.93 to 1.29) & $1.03(0.62$ to 1.71$)$ & $0.90(0.57$ to 1.43$)$ \\
\hline $241-360$ & $1.47(1.34$ to 1.60$)$ & $1.34(1.15$ to 1.55$)$ & 1.19 (1.01 to 1.39$)$ & $1.20(0.72$ to 1.99$)$ & 0.94 (0.59 to 1.49$)$ \\
\hline $481-600$ & $1.71(1.56$ to 1.87$)$ & $1.46(1.25$ to 1.70$)$ & $1.25(1.06$ to 1.48$)$ & $1.48(0.88$ to 2.48$)$ & $0.90(0.56$ to 1.45$)$ \\
\hline$P$ value for trend & $<0.001$ & $<0.001$ & 0.002 & 0.005 & 0.93 \\
\hline \multicolumn{6}{|c|}{$\begin{array}{l}\text { Analysis conducted in new users of PPIs. } T_{0} \text { was set to be the end of the last PPI prescription. } \\
\text { *ICD10 I00-I99 } \\
\text { tICD10 C00-D } 49 \\
\text { झICD10 N00-N99 } \\
\text { §ICD10 A00-B99 }\end{array}$} \\
\hline
\end{tabular}

of PPIs where medically indicated; nevertheless, the findings emphasize the need to promote awareness of potential adverse events of long term PPI use, for better pharmacovigilance, and the need to limit prescription of PPIs to patients where the benefits outweigh potential risks. ${ }^{1}$ Identification of those at high risk of adverse events attributable to taking PPIs is an important knowledge gap and could inform risk stratification and risk mitigation strategies. Future research should also investigate the best way to implement deprescription programs to reduce the unnecessary or un-indicated use of PPIs. ${ }^{5153}$

We designed this study to evaluate the research question using a cohort from a time when the prevalence of PPI prescriptions was lower; and the doses prescribed were lower. Over $80 \%$ of new users of PPIs in our cohort had an initial dose that is equivalent to over-the-counter doses (table 2). That and the findings of increased risk of cause specific mortality with prolonged duration of exposure suggests that prescription PPI use should be limited to well documented indications (where patients may derive benefit), and for a well defined duration-defined by the underlying indication. Over-the-counter use of PPIs should only be for a brief duration of time (generally not to exceed 14 days).$^{54}$ Efforts to target and reduce prolonged use of prescription PPIs without indications and to curtail extended use of over-the-counter PPIs might be a good approach.

Evidence suggests that taking PPIs is associated with an increased risk of cardiovascular disease and chronic kidney disease ${ }^{12122}$; the finding in our study that taking PPIs is associated with an excess mortality due to cardiovascular disease and chronic kidney disease suggests that beyond the occurrence of the adverse events, excess PPI use is linked to loss of life. Furthermore, the results of formal interaction analyses show that the relation between taking PPIs and cause specific mortality (death duecardiovascular diseaseand chronic kidney disease) is not modified by the presence of related baseline comorbid condition, suggesting that the presence of baseline cardiovascular disease or chronic kidney disease does not increase the risk of PPI related cause specific mortality. The pathways in which exposure to PPIs leads to excess cause specific mortality is likely mediated by either worsening of the underlying baseline disease (cardiovascular disease or chronic kidney disease) or the occurrence of de novo disease (cardiovascular disease or chronic kidney disease) which would then heighten the risk of cause specific mortality. Experimental evidence from Yepuri and colleagues suggested a "unifying mechanism" for the association of PPI use with an increased risk of cardiovascular and kidney morbidity and mortality. ${ }^{55}$ The investigators reported that long term exposure to PPIs blunted lysosomal acidification and proteostasis in endothelial cells, increased oxidative stress, impaired endothelial function, and accelerated human endothelial senescence by reducing telomere length. ${ }^{55}$ Our findings of excess mortality due to cardiovascular disease and chronic kidney disease are consistent with this proposed biologic mechanism,

\begin{tabular}{|c|c|c|c|c|c|c|}
\hline \multirow[b]{2}{*}{ Cause of death } & \multirow[b]{2}{*}{ Subcause of death } & \multicolumn{2}{|c|}{ Event rate per $100(95 \% \mathrm{Cl})$} & \multirow{2}{*}{$\begin{array}{l}\text { Excess burden } \\
\text { per } 1000 \\
(95 \% \mathrm{Cl})\end{array}$} & \multicolumn{2}{|c|}{ Hazard ratio $(95 \% \mathrm{Cl})$} \\
\hline & & PPIs & H2 blockers & & Fine and Gray & Cox \\
\hline $\begin{array}{l}\text { Circulatory system } \\
\text { diseases }\end{array}$ & Cardiovascular disease* & $\begin{array}{l}8.87 \\
\text { (8.54 to } 9.23)\end{array}$ & $\begin{array}{l}7.33 \\
\text { (6.65 to } 8.08)\end{array}$ & $\begin{array}{l}15.48 \\
(5.02 \text { to } 25.19)\end{array}$ & $\begin{array}{l}1.22 \\
(1.07 \text { to } 1.40)\end{array}$ & $\begin{array}{l}1.25 \\
\text { (1.10 to } 1.44)\end{array}$ \\
\hline Neoplasms & $\begin{array}{l}\text { Upper gastrointestinal } \\
\text { cancert }\end{array}$ & $\begin{array}{l}0.63 \\
(0.57 \text { to } 0.72)\end{array}$ & $\begin{array}{l}0.46 \\
(0.34 \text { to } 0.6)\end{array}$ & $\begin{array}{l}1.72 \\
(-0.15 \text { to } 3.74)\end{array}$ & $\begin{array}{l}1.38 \\
(0.97 \text { to } 2.09)\end{array}$ & $\begin{array}{l}1.41 \\
(1.00 \text { to } 2.15)\end{array}$ \\
\hline $\begin{array}{l}\text { Infectious and } \\
\text { parasitic diseases }\end{array}$ & $\begin{array}{l}\text { Clostridium difficile } \\
\text { infections§ }\end{array}$ & $\begin{array}{l}0.12 \\
(0.09 \text { to } 0.21)\end{array}$ & $\begin{array}{l}0.06 \\
(0.03 \text { to } 0.12)\end{array}$ & $\begin{array}{l}0.65 \\
(-0.18 \text { to } 1.70)\end{array}$ & $\begin{array}{l}2.09 \\
(0.84 \text { to } 5.73)\end{array}$ & $\begin{array}{l}2.18 \\
(0.86 \text { to } 6.04)\end{array}$ \\
\hline \multicolumn{7}{|c|}{$\begin{array}{l}\text { Subcauses are subcategories of causes of death which exh } \\
\text { supporting a relation between taking PPIs and adverse eve } \\
\text { *ICD10 I21-I24.0, I24.2-I25.2, I25.8-I25.9, I60-I69 } \\
\text { †ICD10 C15.0-C17.0, D00.1-D00.2, D13.0-D13.2, D37.1 } \\
\text { †ICD10 N18-N19 } \\
\text { \$ICD10 A04.7 }\end{array}$} \\
\hline
\end{tabular}




\begin{tabular}{|c|c|c|c|c|c|c|}
\hline \multirow[b]{2}{*}{ Cause of death } & \multirow[b]{2}{*}{ Subcause of death } & \multicolumn{2}{|c|}{ Event rate per $100(95 \% \mathrm{Cl})$} & \multirow{2}{*}{$\begin{array}{l}\text { Excess burden per } \\
1000(95 \% \mathrm{Cl})\end{array}$} & \multicolumn{2}{|c|}{ Hazard ratio $(95 \% \mathrm{Cl})$} \\
\hline & & PPIs & H2 blockers & & Fine and Gray & Cox \\
\hline $\begin{array}{l}\text { Circulatory system } \\
\text { diseases }\end{array}$ & $\begin{array}{l}\text { Cardiovascular } \\
\text { disease* }\end{array}$ & $\begin{array}{l}10.31 \\
\text { (9.84 to } 10.79 \text { ) }\end{array}$ & $\begin{array}{l}8.02 \\
\text { (7.38 to } 8.71)\end{array}$ & $\begin{array}{l}22.91 \\
\text { (11.89 to } 33.57)\end{array}$ & $\begin{array}{l}1.30 \\
(1.15 \text { to } 1.48)\end{array}$ & $\begin{array}{l}1.34 \\
\text { (1.19 to } 1.53)\end{array}$ \\
\hline Neoplasms & $\begin{array}{l}\text { Upper gastrointestinal } \\
\text { cancert }\end{array}$ & $\begin{array}{l}0.69 \\
(0.59 \text { to } 0.85)\end{array}$ & $\begin{array}{l}0.38 \\
(0.27 \text { to } 0.52)\end{array}$ & $\begin{array}{l}3.12 \\
(0.91 \text { to } 5.44)\end{array}$ & $\begin{array}{l}1.83 \\
\text { (1.18 to } 2.99)\end{array}$ & $\begin{array}{l}1.89 \\
\text { (1.21 to } 3.09)\end{array}$ \\
\hline $\begin{array}{l}\text { Genitourinary system } \\
\text { diseases }\end{array}$ & $\begin{array}{l}\text { Chronic kidney } \\
\text { diseaseł }\end{array}$ & $\begin{array}{l}1.08 \\
(0.93 \text { to } 1.31)\end{array}$ & $\begin{array}{l}0.61 \\
(0.48 \text { to } 0.80)\end{array}$ & $\begin{array}{l}4.74 \\
(1.53 \text { to } 8.05)\end{array}$ & $\begin{array}{l}1.78 \\
(1.19 \text { to } 2.66)\end{array}$ & $\begin{array}{l}1.86 \\
\text { (1.24 to } 2.80)\end{array}$ \\
\hline $\begin{array}{l}\text { Infectious and } \\
\text { parasitic diseases }\end{array}$ & $\begin{array}{l}\text { Clostridium difficile } \\
\text { infections§ }\end{array}$ & $\begin{array}{l}0.12 \\
(0.09 \text { to } 0.18)\end{array}$ & $\begin{array}{l}0.07 \\
(0.03 \text { to } 0.15)\end{array}$ & $\begin{array}{l}0.49 \\
(-0.50 \text { to } 1.38)\end{array}$ & $\begin{array}{l}1.71 \\
(0.65 \text { to } 4.92)\end{array}$ & $\begin{array}{l}1.78 \\
\text { (0.68 to } 5.08)\end{array}$ \\
\hline
\end{tabular}

but do not exclude the possible contributions of other mechanisms including those mediated by activation of the heme oxygenase- 1 enzyme in endothelial cells and microbiome perturbation. ${ }^{56-58}$

Analyses by subcauses within the death due to neoplasm category suggested that mortality due to upper gastrointestinal cancer was more evident in those without gastrointestinal indication for use of acid suppression drugs, likely a manifestation of lower baseline risk. The findings are consistent with emerging evidence suggesting that long term exposure to PPIs increases the risk of gastric malignancy. ${ }^{59-67} \mathrm{~A}$ recent study by Cheung and colleagues examined the risk of gastric cancer in a cohort of 63397 patients and reported excess burden among long term users of PPI. ${ }^{66}$ The investigators reported that the adjusted absolute risk difference for PPI use versus non-PPI use for excess gastric cancer was 4.29 (95\% confidence interval 1.25 to 9.54 ) per 10000 person years. ${ }^{66}$ Wan and colleagues conducted a meta-analysis of 926386 patients and found that long term PPI use was associated with a twofold risk of gastric cancer (odds ratio 2.10, 95\% confidence interval 1.10 to 3.09). ${ }^{64}$ The underlying mechanism(s) by which long term exposure to PPIs might increase the risk of gastric cancer is hypothesized to involve gastrin mediated trophic stimulus of gastric mucosa, gastric atrophy, and alteration of gut microbiota and gastric mucosal immunology. ${ }^{586468}$

In our analyses, we observed a graded relation between duration of exposure and the risk of mortality due to chronic conditions including circulatory system diseases, neoplasms, and genitourinary system diseases. Notably, there was no relation between the duration of exposure and the risk of death due to infectious and parasitic diseases, most likely due to the acuteness of the clinical condition where the relation might be idiosyncratic. ${ }^{69}$

Given the observational nature of this study, we carefully considered potential biases which could result in false relations and designed a multipronged causal inference analytic approach to emulate a target randomized trial that would answer the research question. We considered the following strategies: first, we employed a new user design to enhance balance in comparison groups based on pretreatment status, and an active comparator control to reduce the chance of confounding by indication. Second, to avoid capturing reverse causation and to ensure the temporal direction between exposure and diseases that lead to cause specific mortality, we removed all events which occurred within 180 days after first exposure. Third, we applied inverse probability of treatment weighting based on high dimensional propensity scores to create a pseudo cohort whose treatment assignment was independent of measured confounders. ${ }^{70}$ Fourth, to reduce the probability that an observed association between PPIs and causes of death is contributed by unmeasured confounding, we employed an instrumental variable method. ${ }^{71}$ Results from two negative controls which showed no association between PPI use and transportation mortality, and no association between PPI use and death due to peptic ulcer disease, lessen concerns about unmeasured confounding and other biases. In particular, results from our negative control analysis of death due to peptic ulcer disease are consistent with those of multiple randomized controlled trials. ${ }^{43}$ Furthermore, the finding that PPI use was not associated with excess mortality due to digestive system diseases further lends validity to our approach. Taken together, the findings suggest that subjecting our approach to the scrutinous application of negative controls yielded results consistent with a priori expectations and results from randomized controlled trials, suggesting no observable biases in analyses of established relations.

\section{Strengths and limitations of study}

The study has several limitations. The cohort included US veterans who were mostly older, white, and male, which might limit the generalizability of the study results to a broader population. Although our application of several inclusion and exclusion criteria could have introduced selection bias, these criteria are needed for more accurate cohort definition (and new user definition) which will optimize the successful emulation of a target trial. In our analyses, we defined drug exposure based on Department of Veterans Affairs prescription records and by days of supply which might not necessarily be equivalent with days of use since patients can obtain PPIs through over-thecounter purchase, by other means, or may not adhere 
to a Department of Veterans Affairs prescription. Although we applied high dimensional propensity scores, and used instrumental variable methods, our overall approach is inherently limited by the validity of the underlying assumptions. ${ }^{40}$ Furthermore, while we used an active comparator design, and developed strategies to reduce confounding, channeling bias, and other forms of residual confounding might not be completely eliminated. ${ }^{72}$ To obtain sufficient followup, we built a cohort of new users in 2003; as PPI use became more prevalent over the last decade, we anticipate that the proportion of patients where the risk of taking PPIs might outweigh potential benefit could have increased over time and as such our results could have underestimated the true burden of cause specific mortality. The study has several strengths, including the use of national large scale data from a network of integrated health systems, which were captured during routine medical care that minimizes selection bias. We employed a new user design with an active comparator control from a time when $\mathrm{H} 2$ blockers were commonly used, applied instrumental variable and high dimensional propensity score method, and tested positive and negative controls to more accurately estimate the burden of cause specific mortality.

\section{Conclusions}

The results show a consistent excess of cause specific mortality even among patients without documented gastrointestinal indications for acid suppression drugs-an alarming finding which might help guide the design and implementation of deprescription programs to reduce the number of unnecessary or un-indicated PPI prescriptions. The evidence that mortality due to cardiovascular disease, chronic kidney disease, and upper gastrointestinal cancer was not modified by the presence of baseline cardiovascular disease, chronic kidney disease, or upper gastrointestinal cancer, respectively, suggests the need for heightened vigilance among those with and-with equal importancethose at risk of these conditions. The evidence from all available studies suggests that long term PPI use is associated with serious adverse events, including an increased risk of all cause mortality, and our results specifically suggest an increased mortality due to cardiovascular disease, chronic kidney disease, and upper gastrointestinal cancer. Because of the high prevalence of PPI use, the findings have public health implications and underscore the important message that PPIs should be used only when medically indicated and for the minimum duration necessary.

The contents do not represent the views of the United States Department of Veterans Affairs or the United States Government.

Contributors: $Y X, B B, T L, H X, Y Y$, and ZAA developed the research area and study design. $Y X$ and $B B$ acquired the data. $Y X, B B, T L, H X$, $Y Y$, and ZAA analyzed and interpreted the data. $Y X$ and BB performed the statistical analysis. ZAA supervised and mentored the team. Each author contributed important intellectual content during manuscript drafting or revision and accepts accountability for the overall work by ensuring that questions pertaining to the accuracy or integrity of any portion of the work are appropriately investigated and resolved. All authors had full access to the data in the study and can take responsibility for the integrity of the data and the accuracy of the data analysis. ZAA is the guarantor. The corresponding author attests that all listed authors meet authorship criteria and that no others meeting the criteria have been omitted.

Funding: This research was funded by the United States Department of Veterans Affairs and the Institute for Public Health at Washington University in St Louis, MO, USA (ZAA). The funders of this study had no role in study design; collection, analysis, and interpretation of data; writing the report; and the decision to submit the report for publication.

Competing interests: All authors have completed the ICMJE uniform disclosure form at www.icmje.org/coi_disclosure.pdf and declare: no support from any organization for the submitted work; no financial relationships with any organizations that might have an interest in the submitted work in the previous three years; no other relationships or activities that could appear to have influenced the submitted work.

Ethical approval: This research project (study\# 1163689) was reviewed and approved by the Institutional Review Board of the Department of Veterans Affairs Saint Louis Health Care System. Data sharing: All data are available through the United States Department of Veterans Affairs.

The lead author (ZAA) affirms that the manuscript is an honest, accurate, and transparent account of the study being reported; that no important aspects of the study have been omitted; and that any discrepancies from the study as planned have been explained.

The Corresponding Author has the right to grant on behalf of all authors and does grant on behalf of all authors, a non-exclusive license (the corresponding author is a US Government employee) on a worldwide basis to the BMJ Publishing Group Ltd to permit this article (if accepted) to be published in BMJ editions and any other BMJPGL products and sublicences such use and exploit all subsidiary rights, as set out in our license."

This is an Open Access article distributed in accordance with the Creative Commons Attribution Non Commercial (CC BY-NC 4.0) license, which permits others to distribute, remix, adapt, build upon this work non-commercially, and license their derivative works on different terms, provided the original work is properly cited and the use is noncommercial. See: http://creativecommons.org/licenses/by-nc/4.0/.

1 Schoenfeld AJ, Grady D. Adverse Effects Associated With Proton Pump Inhibitors. JAMA Intern Med 2016;176:172-4. doi:10.1001/ jamainternmed.2015.7927

2 Xie Y, Bowe B, Li T, Xian H, Balasubramanian S, Al-Aly Z. Proton Pump Inhibitors and Risk of Incident CKD and Progression to ESRD. J Am SoC Nephrol 2016;27:3153-63. doi:10.1681/ASN.2015121377

3 Li T, Xie Y, Al-Aly Z. The association of proton pump inhibitors and chronic kidney disease: cause or confounding?Curr Opin Nephrol Hypertens 2018;27:182-7. doi:10.1097/ MNH.0000000000000406

4 Xie Y, Bowe B, Li T, Xian H, Yan Y, Al-Aly Z. Risk of death among users of Proton Pump Inhibitors: a longitudinal observational cohort study of United States veterans. BMJ Open 2017;7:e015735. doi:10.1136/bmjopen-2016-015735

5 Hernán MA, Robins JM. Using Big Data to Emulate a Target Trial When a Randomized Trial Is Not Available. Am J Epidemiol 2016;183:75864. doi:10.1093/aje/kwv254

6 VIReC Research User Guide: Veterans Health Administration Decision Support System Clinical National Data Extracts H, IL, U.S. Department of Veterans Affairs. VA Information Resource Center September 2009. https://www.virec.research.va.gov/Resources/RUGs.asp

7 Oliver A. The Veterans Health Administration: an American success story?Milbank Q 2007;85:5-35. doi:10.1111/j.14680009.2007.00475.x

8 Medical Benefits Package VA. Secondary Medical Benefits Package 2019. https://www.va.gov/healthbenefits/resources/publications/ hbco/hbco_medical_benefits_package.asp.

9 VA. National Center for Veterans Analysis and Statistics. Secondary National Center for Veterans Analysis and Statistics 2019. https:// www.va.gov/vetdata/report.asp.

10 Bowe B, Xie Y, Li T, Yan Y, Xian H, Al-Aly Z. Particulate Matter Air Pollution and the Risk of Incident CKD and Progression to ESRD. / Am Soc Nephrol 2018;29:218-30. doi:10.1681/ASN.2017030253

11 Bowe B, Xie Y, Xian H, Balasubramanian S, Al-Aly Z. Low levels of high-density lipoprotein cholesterol increase the risk of incident kidney disease and its progression. Kidney Int 2016;89:886-96 doi:10.1016/j.kint.2015.12.034

12 Bowe B, Xie Y, Xian H, Balasubramanian S, Zayed MA, Al-Aly Z. High Density Lipoprotein Cholesterol and the Risk of All-Cause Mortality among U.S. Veterans. Clin I Am Soc Nephrol 2016;11:1784-93. doi:10.2215/CJN.00730116 
13 Bowe B, Xie Y, Xian H, Li T, Al-Aly Z. Association between Monocyte Count and Risk of Incident CKD and Progression to ESRD. Clin J Am Soc Nephrol 2017;12:603-13. doi:10.2215/CJN.09710916

14 Bowe B, Xie Y, Xian H, Lian M, Al-Aly Z. Geographic Variation and US County Characteristics Associated With Rapid Kidney Function Decline. Kidney Int Rep 2016;2:5-17. doi:10.1016/j. ekir.2016.08.016

15 Bowe B, Xie Y, Li T, et al. Associations of ambient coarse particulate matter, nitrogen dioxide, and carbon monoxide with the risk of kidney disease: a cohort study. The Lancet Planetary health 2017;1:e267-e76. doi:10.1016/S2542-5196(17)30117-1

16 Xie Y, Bowe B, Li T, et al. Blood urea nitrogen and risk of insulin use among people with diabetes. Diabetes and vascular disease research 2018;15:409-16. doi:10.1177/1479164118785050

17 Xie Y, Bowe B, Li T, Xian H, Yan Y, Al-Aly Z. Higher blood urea nitrogen is associated with increased risk of incident diabetes mellitus. Kidney Int 2018;93:741-52. doi:10.1016/j.kint.2017.08.033

18 Xie Y, Bowe B, Xian H, Balasubramanian S, Al-Aly Z. Rate of Kidney Function Decline and Risk of Hospitalizations in Stage 3A CKD. Clin Am Soc Nephrol 2015;10:1946-55. doi:10.2215/CJN.04480415

19 Xie Y, Bowe B, Xian H, Balasubramanian S, Al-Aly Z. Renal Function Trajectories in Patients with Prior Improved eGFR Slopes and Risk of Death. PLoS One 2016;11:e0149283. doi:10.1371/journal. pone.0149283

20 Xie Y, Bowe B, Xian H, Balasubramanian S, Al-Aly Z. Estimated GFR Trajectories of People Entering CKD Stage 4 and Subsequent Kidney Disease Outcomes and Mortality. Am J Kidney Dis 2016;68:219-28. doi:10.1053/j.ajkd.2016.02.039

21 Xie Y, Bowe B, Li T, Xian H, Balasubramanian S, Al-Aly Z. Proton Pump Inhibitors and Risk of Incident CKD and Progression to ESRD. J Am Soc Nephrol 2016;27:3153-63. doi:10.1681/ASN.2015121377

22 Xie Y, Bowe B, Li T, Xian H, Yan Y, Al-Aly Z. Long-term kidney outcomes among users of proton pump inhibitors without intervening acute kidney injury. Kidney Int 2017;91:1482-94. doi:10.1016/j. kint.2016.12.021

23 Bowe B, Xie Y, Li T, et al. The 2016 global and national burden of diabetes mellitus attributable to PM2.5 air pollution. The Lancet Planetary health 2018;2:e301-e12. doi:10.1016/S25425196(18)30140-2.

24 Centers for Disease Control and Prevention. Use of the National Death Index in Health Research. https://www.cdc.gov/nchs/data/ndi/ ndi_bibliography_health_research.pdf.

25 Centers for Disease Control and Prevention. International Classification of Diseases,Tenth Revision (ICD-10). https://www.cdc. gov/nchs/icd/icd10.htm

26 Yoshida K, Solomon DH, Kim SC. Active-comparator design and new-user design in observational studies. Nat Rev Rheumatol 2015;11:437-41. doi:10.1038/nrrheum.2015.30

27 Bowe B, Xie Y, Li T, et al. Changes in the us burden of chronic kidney disease from 2002 to 2016: An analysis of the global burden of disease study. JAMA Netw Open 2018;1:e184412. doi:10.1001/ jamanetworkopen.2018.4412

28 Xie Y, Bowe B, Mokdad AH, et al. Analysis of the Global Burden of Disease study highlights the global, regional, and national trends of chronic kidney disease epidemiology from 1990 to 2016. Kidney Int 2018:94:567-81. doi:10.1016/j.kint.2018.04.011

29 Al-Aly Z, Balasubramanian S, McDonald JR, Scherrer JF, O'Hare AM. Greater variability in kidney function is associated with an increased risk of death. Kidney Int 2012;82:1208-14. doi:10.1038/ ki.2012.276

30 Al-Aly Z, Zeringue A, Fu J, et al. Rate of kidney function decline associates with mortality. J Am Soc Nephrol 2010;21:1961-9. doi:10.1681/ASN.2009121210

31 Franklin JM, Eddings W, Glynn RJ, Schneeweiss S. Regularized Regression Versus the High-Dimensional Propensity Score for Confounding Adjustment in Secondary Database Analyses. Am Epidemiol 2015;182:651-9. doi:10.1093/aje/kwv108

32 Angrist D, Imbens GW, Rubin DB. Identification of Causal Effects Using Instrumental Variables. Journal of the American Statistical Association. 1996:434:444-55. doi:10.1080/01621459.1996.10476902

33 Terza JV, Basu A, Rathouz PJ. Two-stage residual inclusion estimation: addressing endogeneity in health econometric modeling. J Health Econ 2008;27:531-43. doi:10.1016/j.jhealeco.2007.09.009

34 Schneeweiss S, Rassen JA, Glynn RJ, Avorn J, Mogun H, Brookhart MA. High-dimensional propensity score adjustment in studies of treatment effects using health care claims data. Epidemiology 2009;20:512-22. doi:10.1097/ EDE.0b013e3181a663cc

35 Rassen JA, Glynn RJ, Brookhart MA, Schneeweiss S. Covariate selection in high-dimensional propensity score analyses of treatment effects in small samples. Am J Epidemiol 2011;173:1404-13. doi:10.1093/aje/kwr001

36 Rassen JADM, Huang W, Schneeweiss S. Pharmacoepidemiology Toolbox. Secondary Pharmacoepidemiology Toolbox. http://www. hdpharmacoepi.org.
37 Austin PC, Stuart EA. Moving towards best practice when using inverse probability of treatment weighting (IPTW) using the propensity score to estimate causal treatment effects in observational studies. Stat Med 2015;34:3661-79. doi:10.1002/sim.6607

38 Brookhart MA, Wang PS, Solomon DH, Schneeweiss S. Instrumental variable analysis of secondary pharmacoepidemiologic data. Epidemiology 2006;17:373-4. doi:10.1097/01. ede.0000222026.42077.ee

39 Brookhart MA, Wang PS, Solomon DH, Schneeweiss S. Evaluating short-term drug effects using a physician-specific prescribing preference as an instrumental variable. Epidemiology 2006;17:268 75. doi:10.1097/01.ede.0000193606.58671.c5

40 Rassen JA, Brookhart MA, Glynn RJ, Mittleman MA, Schneeweiss S. Instrumental variables I: instrumental variables exploit natural variation in nonexperimental data to estimate causal relationships. J Clin Epidemiol 2009;62:1226-32. doi:10.1016/j. jclinepi.2008.12.005

41 Davies NM, Smith GD, Windmeijer F, Martin RM. COX-2 selective nonsteroidal anti-inflammatory drugs and risk of gastrointestina tract complications and myocardial infarction: an instrumenta variable analysis. Epidemiology 2013;24:352-62. doi:10.1097/ EDE.0b013e318289e024

42 Lipsitch M, Tchetgen Tchetgen E, Cohen T. Negative controls: a tool for detecting confounding and bias in observational studies. Epidemiology 2010;21:383-8. doi:10.1097/ EDE.0b013e3181d61eeb

43 Scally B, Emberson JR, Spata E, et al. Effects of gastroprotectant drugs for the prevention and treatment of peptic ulcer disease and its complications: a meta-analysis of randomised trials. Lancet Gastroenterol Hepatol 2018;3:231-41. doi:10.1016/S24681253(18)30037-2

44 Austin PC. Variance estimation when using inverse probability of treatment weighting (IPTW) with survival analysis. Stat Med 2016;35:5642-55. doi:10.1002/sim.7084

45 Forgacs I, Loganayagam A. Overprescribing proton pump inhibitors. BMJ 2008;336:2-3. doi:10.1136/bmj.39406.449456.BE

46 Choudhry MN, Soran H, Ziglam HM. Overuse and inappropriate prescribing of proton pump inhibitors in patients with Clostridium difficile-associated disease. QJM: monthly journal of the Association of Physicians 2008;101:445-8. doi:10.1093/qjmed/hcn035

47 Zink DA, Pohlman M, Barnes M, Cannon ME. Long-term use of acid suppression started inappropriately during hospitalization. Aliment Pharmacol Ther 2005;21:1203-9. doi:10.1111/j.13652036.2005.02454.x

48 Strid H, Simrén M, Björnsson ES. Overuse of acid suppressant drugs in patients with chronic renal failure. Nephrol Dial Transplant 2003;18:570-5. doi:10.1093/ndt/18.3.570

49 Qato DM, Alexander GC, Conti RM, Johnson M, Schumm P, Lindau ST. Use of prescription and over-the-counter medications and dietary supplements among older adults in the United States. JAMA 2008;300:2867-78. doi:10.1001/jama.2008.892

50 Katz MH. Failing the acid test: benefits of proton pump inhibitors may not justify the risks for many users. Arch Intern Med 2010;170:7478. doi:10.1001/archinternmed.2010.64

51 Linsky A, Simon SR. Reversing gears: discontinuing medication therapy to prevent adverse events. JAMA Intern Med 2013;173:524 5. doi:10.1001/jamainternmed.2013.4068

52 Grady D, Redberg RF. Less is more: how less health care can result in better health. Arch Intern Med 2010;170:749-50. doi:10.1001/ archinternmed 2010.90

53 Yachimski PS, Farrell EA, Hunt DP, Reid AE. Proton pump inhibitors for prophylaxis of nosocomial upper gastrointestinal tract bleeding: effect of standardized guidelines on prescribing practice. Arch Intern Med 2010;170:779-83. doi:10.1001/archinternmed.2010.51

54 FDA. Over-The-Counter (OTC) Heartburn Treatment. https://www.fda. gov/drugs/resourcesforyou/consumers/ucm511944.htm.

55 Yepuri G, Sukhovershin R, Nazari-Shafti TZ, Petrascheck M, Ghebre YT, Cooke JP. Proton Pump Inhibitors Accelerate Endothelial Senescence. Circ Res 2016;118:e36-42. doi:10.1161/CIRCRESAHA.116.308807

56 Becker JC, Grosser N, Waltke C, et al. Beyond gastric acid reduction: proton pump inhibitors induce heme oxygenase-1 in gastric and endothelial cells. Biochem Biophys Res Commun 2006;345:1014 21. doi:10.1016/j.bbrc.2006.04.170

57 Nath KA. Heme oxygenase-1 and acute kidney injury. Curr Opin Nephrol Hypertens 2014;23:17-24. doi:10.1097/01 mnh.0000437613.88158.d3

58 Imhann F, Bonder MJ, Vich Vila A, et al. Proton pump inhibitors affect the gut microbiome. Gut 2016;65:740-8. doi:10.1136/ gutjnl-2015-310376

59 Lai SW, Lai HC, Lin CL, et al. Proton pump inhibitors and risk of gastric cancer in a case-control study. Gut 2018;68:765-7. doi:10.1136/ gutjnl-2018-316371

60 Gueta I, Halkin H, Markovits N, et al. Proton pump inhibitors and the risk for gastric cancer: possible confounding by serum vitamin B 12 . Gut 2017;67:1904. doi:10.1136/gutjnl-2017-315695 
61 Peng YC, Huang LR, Lin CL, et al. Association between proton pump inhibitors use and risk of gastric cancer in patients with GERD. Gut 2018:68:374-6. doi:10.1136/gutjnl-2018-316057

62 Suissa S, Suissa A. Proton-pump inhibitors and increased gastric cancer risk: time-related bias. Gut 2018;67:2228-9. doi:10.1136/ gutjinl-2017-315729

63 Suzuki H, Matsuzaki J. Helicobacter pylori eradication failure may have confounded the recent large-scale health database study that showed proton pump inhibitors increase gastric cancer risk Gut 2017;67:2071-2. doi:10.1136/gutjnl-2017-315698

64 Wan QY, Wu XT, Li N, et al. Long-term proton pump inhibitors use and risk of gastric cancer: a meta-analysis of 926386 participants. Gut 2018;2018;68:762-4. doi:10.1136/gutjnl-2018-316416

65 Brusselaers N, Wahlin K, Engstrand L, Lagergren J. Maintenance therapy with proton pump inhibitors and risk of gastric cancer: a nationwide population-based cohort study in Sweden. BM Open 2017;7:e017739. doi:10.1136/bmjopen-2017-017739

66 Cheung KS, Chan EW, Wong AYS, Chen L, Wong ICK, Leung WK. Long term proton pump inhibitors and risk of gastric cancer development after treatment for Helicobacter pylori: a population-based study. Gut 2018;67:28-35. doi:10.1136/gutjnl-2017-314605

67 Poulsen AH, Christensen S, McLaughlin JK, et al. Proton pump inhibitors and risk of gastric cancer: a population-based cohort study. BrJ Cancer 2009;100:1503-7. doi:10.1038/sj.bjc.6605024
68 Laterza L, Scaldaferri F, Gasbarrini A. Risk factors for gastric cancer: is it time to discard PPIs?Gut 2018;68:176-7. doi:10.1136/ gutinl-2017-315621

69 Strom BL. Pharmacoepidemiology, Fourth Edition ed. Wiley,2005.

70 Schneeweiss S. Automated data-adaptive analytics for electronic healthcare data to study causal treatment effects. Clin Epidemiol 2018;10:771-88. doi:10.2147/CLEP.S166545

71 Nørgaard M, Ehrenstein V, Vandenbroucke JP. Confounding in observational studies based on large health care databases: problems and potential solutions - a primer for the clinician. Clin Epidemiol 2017;9:185-93. doi:10.2147/CLEP.S129879

72 Lobo FS, Wagner S, Gross CR, Schommer JC. Addressing the issue of channeling bias in observational studies with propensity scores analysis. Res Social Adm Pharm 2006;2:143-51. doi:10.1016/j. sapharm.2005.12.001

Supplementary materials: Supplemental tables 1, 2, and 3

Supplementary materials: Supplemental figure 1a-c Supplementary materials: Supplemental figure 2 Supplementary materials: Supplemental methods 